\title{
Competition and Food Intake: A Laboratory Study
}

\author{
Marisa Bucheli (PhD) \\ Mariana Gerstenbluth (MA) \\ Maximo Rossi (PhD) \\ Universidad de la Republica, Uruguay
}

Doi: 10.19044/esj.2018.v14n10p53 URL:http://dx.doi.org/10.19044/esj.2018.v14n10p53

\begin{abstract}
The aim of this paper is to analyze the intake of two types of sweet snacks by women using competitive environments as stressors. We study the effect of competition on food intake from two perspectives: overall consumption and the substitution between two snacks (a "healthy" and a "nonhealthy" snack).

For this purpose we did a laboratory experiment in which the participants were women. They were offered chocolate candies and raisins as they solved several problems. Half of the participants completed the tasks at a noncompetitive piece rate and the other half under a competitive tournament incentive scheme. The results show that at the median the participants' intake was higher under tournament than piece rate payment. Moreover, the increase in food intake was led by a rise in chocolate consumption. We conclude that competition increases the consumption of fat, calories and carbohydrates and thus affects eating behavior and promotes unhealthy patterns. This research contributes to the strand of the literature that focuses on factors that affect the eating behavior which influences health.
\end{abstract}

Keywords: Food intake, competition, laboratory experiment, women

\section{Introduction}

The relationship between stress and food has been extensively studied. Stress is the response to the imbalance between psychosocial demands and resources, i.e., a transactional process between the person and the environment with social and cognitive mediation mechanisms (Steptoe, 1991). Control of food intake is one of them, to the extent that eating disinhibition generates an escape. According to Wallis and Hetherington (2009), by affecting self-control, eating moves the attention from the negative stimulus to an immediate one, food. The higher reported stress, greater feelings of disinhibition occur, promoting hunger and binge eating. 
Furthermore, it is possible that stress increases subjective discount rates, which implies a lower preference for the future, or impatience (Delaney et al., 2014), causing people to re-weigh options (Wright, 1974). Besides, as stress levels increase, individuals are less able to make rational choices (Meichenbaum, 2007), acting as "satisfiers" instead of "optimizers" (Savage and Torgler, 2009).

Several empirical studies support the idea that overeating is a response to stress, since in a high-stress scenario, people tend to consume larger amounts of food (Greeno and Wing, 1994; Habhab et al., 2001; Dallman et al., 2003; Dallman et al., 2005).

Regarding type of food chosen, most empirical work finds that stress creates a preference for sweet (Habhab et al., 1992; Rutledge and Linden, 1998), high-fat (Kandiah et al., 2006; Liu et al., 2007; Ng and Jeffery, 2003; Wardle et al., 2000) and high energy-density foods (Oliver et al., 2000). Overall, it is palatable meals - those that provoke an hedonic reward when eaten- what stressed individuals tend to consume, typically snacks and chocolate, as energy demand is high and time available for eating is short (Wurtman, 1988).

However, some research argues that under certain conditions people do not change their intake under stress, neither in quantity nor in type (Oliver et al., 2000; Oliver and Wardle, 1999).

The results in terms of quantity and type of food are highly variable depending on the type of study. Outside the scope of the laboratory, it can be difficult to obtain reliable information about food intake. Appealing to the individual's memory is not enough when it is necessary to know the exact amount and variation in the composition of food consumed, making it difficult to detect the effect of stress on food intake (Brownell, 1994). Given the above, we make a laboratory experiment. Meanwhile, most of the cases used questionnaires (Oliver and Wardle, 1999; Wallis and Hetherington, 2009; Kandiah et al., 2006; Liu et al., 2007; Ng and Jeffery, 2003; Wardle et al., 2000).

Men and women tend to behave differently in relation to food. Under stress, females tend to eat more junk food, while males do not (Zellner et al., 2006; Zellner et al., 2007). Females who overeat during stressful situations may do so as a result of an eating style characterized by the inability to maintain control over self-imposed rules, which is typical in the case of restrained and emotional eaters. Stress triggers disinhibition, threatening selfimage. Problems in eating behavior in males and females should be approached in different ways since associations between intake during stress and other eating variables differ substantially (Weinstein et al., 1997).

Gender differences also arise when studying different kind of stressors. Competition is well known as an important stressor by imposing 
uncontrollability and social-evaluative threat (Dickerson and Kemeny, 2004). Depending on others' performance provides uncertainty while it is also a threat for self-esteem (Buckert et al., 2014). Gneezy et al. (2003) find that women perform worse than men in competitive environments.

Although competition has been a central issue in economics, its effects on people's health had not been studied. So, the aim of laboratory study reported here is to analyze the intake of two types of sweet snacks by women using competitive environments as stressors.

\section{Methods}

A total of 87 female students participated in the experiment over 13 sessions in which they had to solve several tasks. To create non-competitive and competitive sessions we manipulated the payment scheme (piece-rate under non-competition and tournament payment scheme under competition). Because the effect of competition might be different under a single-sex or mixed-sex environment, we organized women's sessions and sessions where both men and women were present. Participants were randomly assigned to the sessions.

Two bowls with food (raisins and chocolate candies) and a bottle of water were available to each subject. We pre-set the time of the sessions to guarantee that exposure time to food was identical for all subjects. Eating (as a response to stress) may be observed during the stressful situation or after its end. Thus, we designed a session divided into three parts seeking to produce the highest stress level in the first one and the lowest level in the third one. The exposure time was around 30 minutes, with a minimum value of 27 and a maximum value of 35 .

\section{Participants}

The subjects were recruited through posters and verbal information in regular class time at the Universidad de la República (Uruguay). Those interested in participating were asked to fill an on-line questionnaire that covered several topics (see Annex 1). Among them, we asked some questions about health status in order to recruit individuals that declared not to have diabetes or high cholesterol, that is, who did not have health-related eating restrictions.

Previous experiments indicate that under a competitive environment, the performance of women is higher when they compete with women than men (Gneezy et al., 2003). Besides, women are less prone than men to enter in competition (Gneezy et al., 2009; Niederle and Vesterlund, 2007). These findings led us to think that the stress level provoked by competition would be deeper if women competed with men than only women. Thus, though we were 
interested only in the women's behavior, we recruited men with the purpose of creating a mixed-sex environment in some sessions.

The participants numbered 87 women and 40 men. Most of them were undergraduate students of economics, political science, sociology and social work. Women were randomly assigned to different environments: 23 participated in a single-sex non-competitive session, 24 in a mixed-sex noncompetitive session, 21 in a single-sex competitive session and 19 in a mixedsex competitive session.

\section{Tasks}

As already mentioned, Part I was dedicated to time scheduled tasks. The subjects were asked to do 5 types of tasks that appeal to different abilities. All subjects did the same tasks in the same order.

In the first task (W), each subject had a blank sheet of paper in which at the top the letters A C O P I R were printed. She had one minute to write words made from (only) at least three of those letters.

In the second task $(\mathrm{S})$, the subject had a sheet of paper with 37 rows. A series of numbers and/or letters that followed a logical order was displayed in each row. She had to write the number or letter that followed the printed series. It was not required to follow the order of the rows (series could be skipped). This task lasted two minutes

In the third task $(\mathrm{M})$ the subject had one minute to solve mazes that were presented in printed sheets (12 mazes).

The fourth task (T) was presented in a table of four rows and six columns. The header rows were the letters A E F I. The header columns were: cities, rivers, mammals, flowers/plants, countries and fruits. The subject had a minute to write in the cells a word that started with the header row letter and belonged to the set of elements indicated in the header column.

The last task $(\mathrm{O})$ consisted on solving basic mathematical operations in two minutes. The sheet displayed 37 rows of operations. It was not required to follow a particular order.

We informed the subjects that, according to the pilot test prior to the experiment, it was not feasible that they complete the tasks in the pre-set time.

In Part II we asked the participant to guess her relative position in each task within a group of 4 subjects. Under the non-competitive environment we created the groups just before the beginning of the second part. Under the competitive environment the groups were created at the beginning of the session. In the mixed-sex sessions, the groups were formed by two men and two women.

In Part III we asked the subject to choose ten times between two lotteries. 


\section{Treatments and payments}

We created a non-competitive and a competitive environment by manipulating the payment schemes of Part I.

Under the non-competitive environment, we used a piece rate payment, that is, the participant was paid according to the number of hits. The piece rate was fixed on the base of the performance obtained in a previous pilot test. As the number of hits in each task was different, the rate of each task was different too. ${ }^{2}$

Under the competitive environment, we implemented a tournament. We created groups of four subjects and only the winner (the subject with most hits) received a payment. The rate of each hit was calculated on the basis that the expected spending on the group was similar under both environments. ${ }^{3}$

The rates were informed at the beginning of the session. We also informed them that only one task, randomly chosen, was paid. Participants were also paid for a randomly chosen guess of Part II and a randomly chosen lottery of Part III. The participants under tournament were paid in addition a showing-up sum of 200 Uruguayan pesos to avoid that some subjects received no payment. They were informed about this payment only at the end of the session in order to not discourage effort. dollars).

On average, the total payment was 423 Uruguayan pesos (21 American

\section{Food}

On the table in front of each subject, there was a bottle of water and two bowls containing chocolate candies $(50 \mathrm{~g})$ and raisins $(50 \mathrm{~g})$. The food selection was based on the findings by Zellner et al. (2006, 2007) who performed a test that indicated that, being both popular snacks, raisins were considered healthier than chocolate candies.

In Table 1 we present the nutritional values that are reported in the packages of the chocolate candies and raisins offered to the participants. As shown in the column "calories", chocolate candies are more energy-dense than raisins. They also have more fat but both have similar amount of carbohydrates.

\footnotetext{
${ }^{2}$ The rates (in Uruguayan pesos) for each task were the following: $\mathrm{W}, 30 ; \mathrm{S}, 15 ; \mathrm{M}, 35 ; \mathrm{T}$, $35 ; \mathrm{O}, 15$.

${ }^{3}$ As in the pilot test the performance was better under tournament than piece rate system, the tournament rates were less than four times the piece rates. In Uruguayan pesos, for each task the rates were the following: W, 65; S, 45; M, 100; T, 90; O, 40.
} 
Table 1. Nutritional information of the food offered to the participants

\begin{tabular}{|c|c|c|c|}
\hline & Calories (kcal) & Fat $(\mathrm{g})$ & Carbohydrates $(\mathrm{g})$ \\
\hline Chocolate candies $(50 \mathrm{~g})$ & 234.0 & 8.4 & 38.0 \\
\hline Raisin $(50 \mathrm{~g})$ & 156.7 & 0.0 & 38.3 \\
\hline
\end{tabular}

The bowls were weighed before and after the session. We used nondischargeable bowls for our control and to avoid subjects taking food intended for other persons. All the bowls were available after the sessions.

\section{Implementation}

The room where the experiment took place had tables at the sides of a corridor where the subjects were randomly seated upon their arrival. In the mixed-sex sessions, we arranged alternating rows of women and men. The two first rows were close to each other and a little further away from the third, which was close to the fourth, etc. This disposition facilitated the formation of groups of four subjects. In the mixed-sex sessions, it also facilitated the formation of groups of two men and two women.

At the beginning of the session we distributed sheets with the instructions of the first part of the experiment ( 5 tasks with exercises) that were read aloud. In the second paragraph, the subjects were thanked for their participation and were offered to snack and drink. At this moment, two bowls and one bottle of water were put on each table.

The time measuring of food exposure began at this moment. On the base of a pilot test we expected the experiment to last 30 minutes from that point. The description that follows shows that we took actions to ensure that all subjects had the same time exposure to food and that each part (which provoked different level of stress) lasted the same amount of time in all sessions. However, subjects may (and some did) put all the desired food in their mouths or palms of the hands just before leaving the room.

The instructions of Part I contained an explanation of the five tasks and the scheme of payment and rates. In the competitive environment sessions, the groups were formed and the subjects were asked to look at their competitors in order to make competition salient. As the tasks to solve were well-known board-games, doubts were few in all sessions. Thus, as we expected, the time spent on reading the instruction was similar in the pilot test and in all the sessions.

Once this set of instructions was read, Part I began. A pre-recorded tape of bell sounds was used to indicate the start and end of each task. No questions were allowed once the tape was played. To do each task, the subject had a booklet (a sheet of paper folded in two). The front page reminded the general rules of the task and the rate. The task itself (the letters to form words, the mathematical operations to solve, etc.) was visible once the booklet was opened. Table 2 reports the recorded time taken in these tasks. 
Table 2. Timed intervals of the sessions

\begin{tabular}{|c|c|c|}
\hline $\begin{array}{c}\text { Beginning of } \\
\text { the interval }\end{array}$ & Actions during the interval & $\begin{array}{c}\text { Ellapsed time until } \\
\text { the next interval }\end{array}$ \\
\hline $\begin{array}{c}\text { Provision of } \\
\text { food and } \\
\text { water }\end{array}$ & Instructions were read & 6 minutes \\
\hline Bell 1 & Booklet W was distributed & $1 / 2$ minute \\
\hline Bell 2 & Participants did task W & 1 minute \\
\hline Bell 3 & Booklet S was distributed & $1 / 2$ minute \\
\hline Bell 4 & Participants did task S & $1 / 2$ minute \\
\hline Bell 5 & Booklet M was distributed & 1 minute \\
\hline Bell 6 & Participants did task M & $1 / 2$ minute \\
\hline Bell 7 & Booklet T was distributed & 1 minute \\
\hline Bell 8 & Participants did task T & $1 / 2$ minute \\
\hline Bell 9 & Booklet O was distributed & 2 minutes \\
\hline Bell 11 & Participants did task O & $1 / 2$ minute \\
\hline Bell 12 & The tape is turned off & 4 minutes \\
\hline Part 2 & Instructions were read and participants did the tasks & 10 minutes \\
\hline Part 3 & Instructions were read and participants did the tasks &.-- \\
\hline End & Participants went to another room & \\
\hline
\end{tabular}

After Part 1, the subjects received the instructions of Part 2 and did the required task. In the case of non-competitive environment, the groups were formed when reading the instructions of Part 2 following the same rules as in the competitive environment. Finally, subjects did Part 3. In both parts, instructions were read aloud and questions were allowed. The expected time of each part is reported in Table 2 .

At the end of the experiment, the subjects were told to go to another room to draw the tasks to be paid. We did a draw for each subject. The payments were done some days after the experiment because we needed time to count the hits of each subject.

\section{Data analysis}

We aim to analyze the difference of intake due to competition. The strategy consists of comparing consumption (measured in grams, calories, fat and carbohydrates) between the group of participants paid by piece rate and by tournament.

We compare mean values using mean tests of independent samples and we perform an estimation in which the dependent variable is alternatively the consumption of raisin, chocolate and total food. The explanatory variables are: a) "tournament" that takes a value of 0 under piece rate payment and 1 under tournament; b) "mixed-sex" that takes a value of 1 under mixed-sex environment and 0 under single-sex environment; c) an interactive value of "tournament" and "mixed-sex". We estimate this effect using OLS. Thus, the estimated coefficient associated with the variable "tournament" is interpreted 
as the average change of consumption due to being submitted to a competitive environment.

We also compare the overall distribution and perform the Kolmorgonov-Smirnov test. To assess the effect at different positions of the distribution of consumption (percentiles 25, 40, 50, 60 and 75) we estimate quantile regressions. The estimated coefficient obtained with a quantile regression on percentile $\mathrm{q}$ is the effect of competition in of the intake distribution at percentile $q$.

\section{Results}

\section{Average results}

In Table 3 we present the average consumption under the two scenarios. In all sessions, participants on average ate more grams of chocolate than raisins. The same pattern was found under the piece rate payment and under tournament. The independent-samples mean-tests indicate that these differences are significant ( $\mathrm{p}=0$ in all tests).

Table 3. Average consumption (standard errors in italics)

\begin{tabular}{ccccc} 
& Grams & Calories & Fat & Carbohydrates \\
\hline All sessions & & & & \\
Chocolate & 13.8 & 64.7 & 2.3 & 10.5 \\
& 1.6 & 7.6 & 0.3 & 1.2 \\
Raisins & 4.0 & 12.7 & 0.0 & 3.1 \\
& 1.0 & 3.1 & 0.0 & 0.8 \\
Total & 17.9 & 77.3 & 2.3 & 13.6 \\
& 2.0 & 8.7 & 0.3 & 1.6 \\
Piece rate & & & & \\
Chocolate & 11.8 & 55.2 & 2.0 & 9.0 \\
& 2.1 & 9.9 & 0.4 & 1.6 \\
Raisins & 3.1 & 9.7 & 0.0 & 2.4 \\
& 1.1 & 3.3 & 0.0 & 0.8 \\
Total & 14.9 & 64.8 & 2.0 & 11.3 \\
& 2.7 & 11.5 & 0.4 & 2.1 \\
Thournament & & & & \\
Chocolate & 16.2 & 75.8 & 2.7 & 12.3 \\
& 2.5 & 11.5 & 0.4 & 1.9 \\
Raisins & 5.2 & 16.2 & 0.0 & 4.0 \\
& 1.8 & 5.5 & 0.0 & 1.3 \\
Total & 21.4 & 92.0 & 2.7 & 2.3 \\
& 3.1 & 12.9 & 0.4 & \\
\hline
\end{tabular}

Overall intake was lower under piece rate payment than in the tournament. This result is the same for all the consumption measures 
considered. Besides, when considering the two different types of food separately, the same pattern is found. We conducted independent-samples mean-tests and we find out that, regardless of the measure, these differences were not significant. Thus, based on the average values, we cannot conclude that competition increases the intake.

\section{Distribution functions}

To illustrate the overall distribution of consumption under the piece rate payment and the tournament, we compute the cumulative distribution function (CDF) of grams, calories, fat and carbohydrates (see Figure 1).

The CDF for piece rate and tournament overlap at the lowest percentiles (value 0). Indeed 16 subjects did not eat anything (10 under piece rate and 6 under tournament).

The shapes of the CDF for piece rate and tournament are different between percentiles 40 and 80 . In terms of grams and carbohydrates, the comparison is unambiguous: the $\mathrm{CDF}$ for piece rate lies over the CDF for tournament, suggesting that competition is associated with an increase of consumption. In terms of calories and fat, the CDFs intersect between percentiles 20 to 40 which do not allow us to extract an unambiguous ranking.

We calculated the Kolmorgonov-Smirnov test to find out the statistical significance of different shapes. We conclude that the piece rate payment group contains smaller values than the tournament group in terms of grams $(\mathrm{p}=0.033)$, calories $(\mathrm{p}=0.033)$, fat $(\mathrm{p}=0.082)$ and carbohydrates $(\mathrm{p}=0.033)$.

Figure 1. Cumulative distribution function of consumed grams, calories, fat and carbohydrates under piece rate payment and tournament.

\section{Distribution functions}
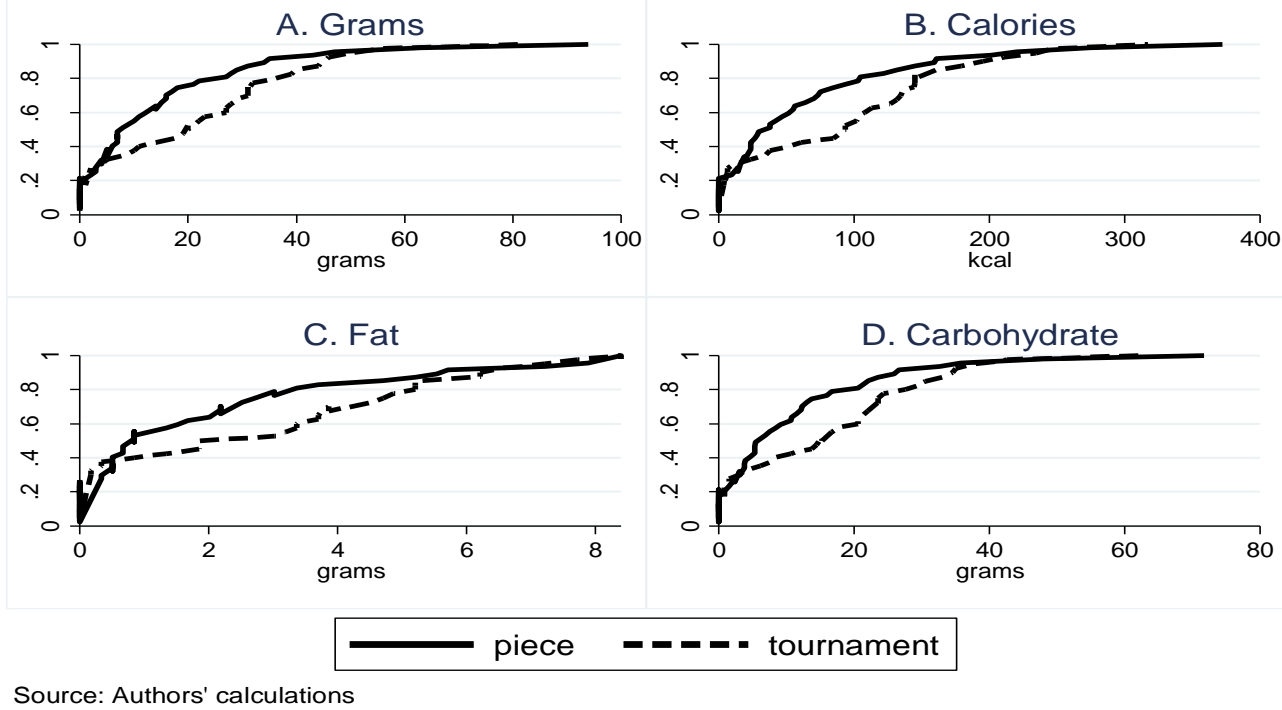
In sum, the CDFs indicate that in the tournament scenario subjects tended to have a higher intake (measured in grams, calories, fat and carbohydrate) than in the piece rate scenario. According to the graphics this effect is stronger around the median of the distribution.

\section{Estimated effects of the tournament}

In Table 4 we present the results of the estimated effects of the tournament environment. We find a positive and significant average effect (of around 10 grams) on the overall consumed grams. It is also positive and significant situated between percentiles 40 and 60; at the median, the tournament provoked an increase of intake equivalent to 12 grams. We also report the effect of tournament on raisins and chocolate separately. We obtain a significant increase of chocolate consumption for subjects in the $50^{\text {th }}$ and $60^{\text {th }}$ percentiles whereas there is no effect on the consumption of raisins. These results suggest that the growth of consumed grams around the median observed in Figure 1 is led by the increase of chocolate intake.

We expect that calories, fat and carbohydrate are higher under tournament than piece rate payment because competition causes total intake to grow. The effect on calories and fat would be amplified by the fact that the growth of intake stems mostly by the rise of chocolate (and not raisin) consumption. As reported in Table 4, on average tournament increases calories (around $40 \mathrm{kcal}$ ) and carbohydrates (7 grams) but not fat. We find positive effects on percentiles 40 to 60 of calories and carbohydrate, and on percentiles 50 and 60 of fat.

Table 4. Estimated effect of tournament on consumed grams, calories, fat and carbohydrates (standard deviations in parenthesis)

\begin{tabular}{|c|c|c|c|c|c|c|}
\hline \multirow[t]{2}{*}{ Position } & \multicolumn{3}{|c|}{ Grams } & \multirow[t]{2}{*}{ Calories } & \multirow[t]{2}{*}{ Fat } & \multirow[t]{2}{*}{ Carbohydrates } \\
\hline & Total & Raisins & Chocolate & & & \\
\hline Mean & $9.745^{*}$ & 3.863 & 5.882 & $39.63^{*}$ & 0.988 & $7.432 *$ \\
\hline 25 & $\begin{array}{c}5 \\
(6.267)\end{array}$ & $\begin{array}{c}0 \\
(0)\end{array}$ & $\begin{array}{c}-1 \\
(3.623)\end{array}$ & $\begin{array}{c}20.39 \\
(29.04)\end{array}$ & $\begin{array}{c}-0.168 \\
(0.973)\end{array}$ & $\begin{array}{c}3.800 \\
(5.423)\end{array}$ \\
\hline 40 & $\begin{array}{c}12^{*} \\
(7.101)\end{array}$ & $\begin{array}{c}0 \\
(0.799)\end{array}$ & $\begin{array}{c}7 \\
(5.795)\end{array}$ & $\begin{array}{l}59.25^{*} \\
(33.12)\end{array}$ & $\begin{array}{c}1.176 \\
(1.188)\end{array}$ & $\begin{array}{l}9.093 * \\
(5.054)\end{array}$ \\
\hline 50 & $\begin{array}{c}12^{*} \\
(6.618)\end{array}$ & $\begin{array}{c}0 \\
(1.882)\end{array}$ & $\begin{array}{c}14^{*} \\
(7.070)\end{array}$ & $\begin{array}{c}59.49 * * \\
(29.91)\end{array}$ & $\begin{array}{l}2.352^{*} \\
(1.048)\end{array}$ & $\begin{array}{l}9.120^{*} \\
(4.743)\end{array}$ \\
\hline 60 & $\begin{array}{c}15 * * \\
(6.239)\end{array}$ & $\begin{array}{c}1 \\
(2.299)\end{array}$ & $\begin{array}{c}12^{*} \\
(6.239)\end{array}$ & $\begin{array}{c}71.59 * * * \\
(21.52)\end{array}$ & $\begin{array}{l}2.016^{*} \\
(1.391)\end{array}$ & $\begin{array}{l}11.51^{* * *} \\
(6.580)\end{array}$ \\
\hline 75 & $\begin{array}{c}14 \\
(8.610)\end{array}$ & $\begin{array}{c}4 \\
(4.963) \\
\end{array}$ & $\begin{array}{c}10 \\
(8.278) \\
\end{array}$ & $\begin{array}{c}59.85 \\
(37.68)\end{array}$ & $\begin{array}{c}1.680 \\
(0.711)\end{array}$ & $\begin{array}{c}10.71 \\
(4.162)\end{array}$ \\
\hline $\begin{array}{r}\text { We re } \\
\text { regressi } \\
\text { following } \\
\text { under si }\end{array}$ & $\begin{array}{l}\text { hestim } \\
\text { iates: a } \\
\text { ex envir }\end{array}$ & $\begin{array}{r}* * * \mathrm{p} \\
\text { efficient } \\
\mathrm{d} \text { deviat } \\
\text { variabl } \\
\text { t; an int } \\
\text { to }\end{array}$ & $\begin{array}{l}\text { Notes: } \\
1, * * \mathrm{p}<0 . \\
\text { the "tourna } \\
\text { (in parenthe } \\
\text { t takes a va } \\
\text { tive value o } \\
\text { ment envir }\end{array}$ & $\begin{array}{l}\text { " }<<0.1 \\
\text { te" variabl } \\
\text {. In the est } \\
\text { of } 1 \text { under } \\
\text { e dummies } \\
\text { lent }\end{array}$ & $\begin{array}{l}\text { the OLS } \\
\text { tion we } \\
\text { red-sex } \\
\text { t captur }\end{array}$ & $\begin{array}{l}\text { d quantiles } \\
\text { include the } \\
\text { ronment and } 0 \\
\text { ixed-sex and }\end{array}$ \\
\hline
\end{tabular}




\section{Conclusion}

We did an experiment in which the subjects were paid according to their performance in different type of exercises. Half of them participated in non-competitive sessions and the other half in competitive sessions. We created the competitive environment by manipulating the payment system: a piece rate payment for hit and a tournament. All the participants were offered chocolate candies and raisins.

The obtained results are in line with the findings of most of the studies of the stress effect on food consumption and food choice. Indeed, the intake of participants subjected to competition was higher around the median as a result of an increase of chocolate consumption. Thus, competition had a positive effect on calories, fat and carbohydrates not only because of the increase of consumption but also because of the characteristics of the chosen food.

This result supports the view that people subjected to competition tend to overeat and to choose palatable food. We interpret that competition acts as a stressor. In stressing situations, as palatability is a marker of energetic food, people tend to choose this type of meal in order to recover energy.

Several mechanisms may link competition and stress. In a study of the gender difference in the entry to competition, Niederle and Versterlund (2007) review the main reasons that make people to avoid competition. These reasons are a source of the stress provoked by competition. Aspects like displeasure for competition and lack of self-confidence would affect the level of stress of an individual forced to compete. Besides, aversion to risk affects the preferences for the payment system so a tournament would provoke an increase of stress level of risk-averse individuals. Finally, aversion to feedback makes competition stressing. Being involved in a competitive environment implies that the individual would eventually be aware of his negative relative performance. Thus, competition might be threatening individual's ego. These reasons might be present in our experiment since previous research indicates that all these characteristics are more frequent among women than men.

This research contributes to the strand of the literature that focuses on factors that affect the eating behavior which influences health. In the modern world in which competition is a key factor in the organization of society, our experiment is especially relevant as we find that competition triggers overeating and consumption of high energy and fat food. Being aware of this result is particularly important in a context in which there is a wide variety of palatable and cheap food. These factors contribute to imposing conditions for the spread of eating- related health problems.

\section{References:}

1. Buckert, M., Schwieren, C., Kudielka, B. and Fiebach, C. (2014).Acute stress affects risk taking but not ambiguity aversion. 
Frontiers in Neuroscience. Vol 8. Doi:10.3389/fnins.2014.00082 2014

2. Dallman, M. F., Pecoraro, N. C., \& la Fleur, S. E. (2005). Chronic stress and comfort foods: self-medication and abdominal obesity. Brain, behavior, and immunity, 19(4), 275-280.

3. Dallman, M. F., Pecoraro, N., Akana, S. F., La Fleur, S. E., Gomez, F., Houshyar, H. \& Manalo, S. (2003). Chronic stress and obesity: a new view of "comfort food". Proceedings of the National Academy of Sciences, 100(20), 11696-11701.

4. Dickerson, S. S., \& Kemeny, M. E. (2004). Acute stressors and cortisol responses: a theoretical integration and synthesis of laboratory research. Psychological bulletin, 130(3), 355.

5. Gneezy, U.; Niederle, M. \& Rustichini, A. (2003). Performance in Competitive Environments: Gender Differences. The Quarterly Journal of Economics, 118(3): 1049-1074.

6. Gneezy U., Leonard, K.L. \& List, J.A. (2009). Gender Differences in Competition: Evidence from a Matrilineal and a Patriarchal Society. Econometrica, 77(5): 1637-1644.

7. Greeno, C. G., \& Wing, R. R. (1994). Stress-induced eating. Psychological bulletin, 115(3), 444-464

8. Habhab, S., Sheldon, J. P., \& Loeb, R. C. (2009). The relationship between stress, dietary restraint, and food preferences in women. Appetite, 52(2), 437-444.

9. Kandiah, J., Yake, M., Jones, J., \& Meyer, M. (2006). Stress influences appetite and comfort food preferences in college women. Nutrition Research, 26(3), 118-123.

10. Liu, C., Xie, B., Chou, C. P., Koprowski, C., Zhou, D., Palmer, P, Sun P, Guo Q, Duan L, Sun X, \& Anderson Johnson C.A. (2007). Perceived stress, depression and food consumption frequency in the college students of China Seven Cities. Physiology \& behavior, 92(4), 748-754.

11. Meichenbaum, D. (2007). Stress inoculation training: A preventative and treatment approach. Principles and practice of stress management, 3, 497-518.

12. Ng, D. M., \& Jeffery, R. W. (2003). Relationships between perceived stress and health behaviors in a sample of working adults. Health Psychology, 22(6), 638.

13. Niederle, M \& Vesterlund, L. (2007). Do Women Shy Away From Competition? Do Men Compete Too Much? The Quarterly Journal of Economics, 122(3): 1067-1101.

14. Oliver, G., \& Wardle, J. (1999). Perceived effects of stress on food choice. Physiology \& behavior, 66(3), 511-515. 
15. Oliver, G., Wardle, J., \& Gibson, E. L. (2000). Stress and food choice: a laboratory study. Psychosomatic medicine, 62(6), 853-865.

16. Rutledge, T., \& Linden, W. (1998). To eat or not to eat: affective and physiological mechanisms in the stress-eating relationship. Journal of Behavioral Medicine, 21(3), 221-240.

17. Savage, D. A., \& Torgler, B. (2012). Nerves of steel? Stress, work performance and elite athletes. Applied Economics, 44(19), 24232435.

18. Steptoe, A. (1991). Invited review: The links between stress and illness. Journal of psychosomatic research, 35(6), 633-644.

19. Wallis, D. J., \& Hetherington, M. M. (2009). Emotions and eating. Self-reported and experimentally induced changes in food intake under stress. Appetite,52(2), 355-362.

20. Wardle, J., Steptoe, A., Oliver, G., \& Lipsey, Z. (2000). Stress, dietary restraint and food intake. Journal of psychosomatic research, 48(2), 195-202.

21. Weinstein, S. E., Shide, D. J., \& Rolls, B. J. (1997). Changes in food intake in response to stress in men and women: psychological factors. Appetite, 28(1), 7-18.

22. Wright, P. (1974). The harassed decision maker: Time pressures, distractions, and the use of evidence. Journal of Applied Psychology, 59(5), 555.

23. Wurtman, J. J. (1988). Carbohydrate craving, mood changes, and obesity. Journal of Clinical Psychiatry.

24. Zellner, D. A., Loaiza, S., Gonzalez, Z., Pita, J., Morales, J., Pecora, D., \& Wolf, A. (2006). Food selection changes under stress. Physiology \& Behavior,87(4), 789-793.

25. Zellner, D. A., Saito, S., \& Gonzalez, J. (2007). The effect of stress on men's food selection. Appetite, 49(3), 696-699. 


\section{Annex 1. Questionnaire}

Welcome. This is the questionnaire for those enrolled in the experiment. Thanks for filling it.

* Required

E-mail *

E-mail *

(repeat)

Gender *

○ M

○ F

Do you like animals? *

○ $Г$ Yes

○ No

\section{Do you suffer from any of these diseases? *}

○ Diabetes

○ Cholesterol

○ Hypertension

- Celiac disease

- Non

\section{Income level *}

Put yourself, according to your household income, in the next scale from 1 to 10, where 1 represents the poorest person and 10 the richer.

$\begin{array}{llllllllll}1 & 2 & 3 & 4 & 5 & 6 & 7 & 8 & 9 & 10\end{array}$

$\underset{\text { poor }}{\text { Extreme }} \quad \mathrm{C} \quad \mathrm{C} C \mathrm{C} \quad \begin{gathered}\text { Extreme } \\ \text { rich }\end{gathered}$

Do you have children?

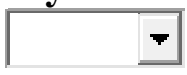

Age *

To take care of your body you: *

$\circ \quad$ Do anything 
○ Do exercise

○ Diet

Indicate your main faculty

Please mark all the options that are suitable for you to attend the session.

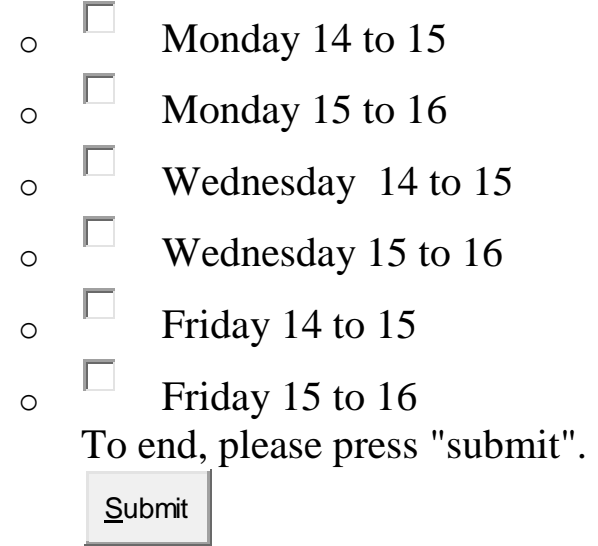

